\title{
Case report of sertoli-leydig cell tumor of bilateral ovaries in a woman with 46XYkaryotype
}

\author{
Dutta $A^{1}$, Borah S.R ${ }^{2}$, Saikia $\mathbf{P}^{3}$, Taye $M^{4}$ \\ ${ }^{1}$ Dr. Aparna Dutta, Assistant Professor, Department of Pathology, ${ }^{2}$ Dr. Smriti Rekha Borah, PGT, Department of \\ Pathology, ${ }^{3}$ Dr. Projnan Saikia, Professor and Head of the Department, Department of Pathology, ${ }^{4}$ Dr. Milan Taye, \\ Department of Obstetrics and Gynecology; all authors are affiliated with AMCH.
}

Address for Correspondence: Dr. Smriti Rekha Borah, Assam Medical College and Hospital, Designation: Post Graduate Trainee, Address: Department of Pathology, Assam Medical College and Hospital, Dibrugarh, Assam, Email id: smriti10borah@gmail.com

\begin{abstract}
Sertoli-Leydig Cell Tumors are rare constituting less than $0.5 \%$ of ovarian neoplasms and usually unilateral. Average age of presentation is 25 years. We report the case of a 23-year-old unmarried woman who presented with primary amenorrhea and 8 months history of intermittent pain over left lower abdomen. Transvaginal scan revealed rudimentary uterus with left ovarian cyst with mural nodules. Cytogenetic study revealed 46XY karyotype. Histopathological examination of specimen received after surgeryshowed well-differentiated Sertoli-Leydig Cell Tumor in sections from bilateral ovaries and Serous Surface Papilloma in a section from left ovary. Diagnosis is based on morphological features. Prognosis depends on stage and degree of differentiation.
\end{abstract}

Keywords: Primary amenorrhea, Sertoli, Leydig, 46XY

\section{Introduction}

Sertoli-Leydig Cell Tumor (SLCT) is a rare ovarian tumor belonging to the group of sex-cord stromal tumors. These constitute less than $0.5 \%$ of ovarian tumors. The average age of presentation is 25 years. Most tumors are unilateral [1]. The characteristic features of these tumors are the presence of testicular structures that produce androgens that lead to symptoms of virilization depending on the quantity of androgen production. These tumors are also characterized by the degree of differentiation of structures in them, the presence of which determines whether the tumors are benign or malignant [2]. We here present a case report of Sertoli-Leydig Cell Tumor having the rarity of bilateral presentation and male karyotype in a 23 -yearold phenotypically female patient.

\section{Case Report}

A 23-year-old unmarried woman presented to the Gynecology OPD with primary amenorrhea and a history of intermittent pain over left lower abdomen for 8 months. Physical examination revealed hirsutismand normal stature. Cytogenetic study revealed 46 XY karyotype (male genome). Transvaginal scan showed rudimentary uterus and left ovarian cyst with mural nodules. She was diagnosed as a case of primary amenorrhea with gonadal dysgenesis in the Gynecology Department and she thereafter underwent bilateral gonadectomy with left sided cystectomy. On gross examination of the specimen sent for histopathological examination, the right ovary showed a smooth grayish-white solid mass of size $(2 X 1) \mathrm{cm}$ and left ovary showed a smooth grayish-white solid-cystic mass of size (5X4)cm. Microscopically, section from both the ovaries showed solid tubules of dark blue sertoli cells and the stroma containedleydig cells with pale, vacuolated to eosinophilic cytoplasm.

Manuscript received: $30^{\text {th }}$ April 2017

Reviewed: $10^{\text {th }}$ May 2017

Author Corrected: $19^{\text {th }}$ May 2017

Accepted for Publication: $25^{\text {th }}$ May 2017 
This indicated a well-differentiated form of SLCT. Serous Surface Papilloma was seen in a section from left ovary. Also, the finding of 46XY karyotype in phenotypically female patient appears to be consistent with the pure gonadal dysgenesis syndromeknown as Swyer syndrome.
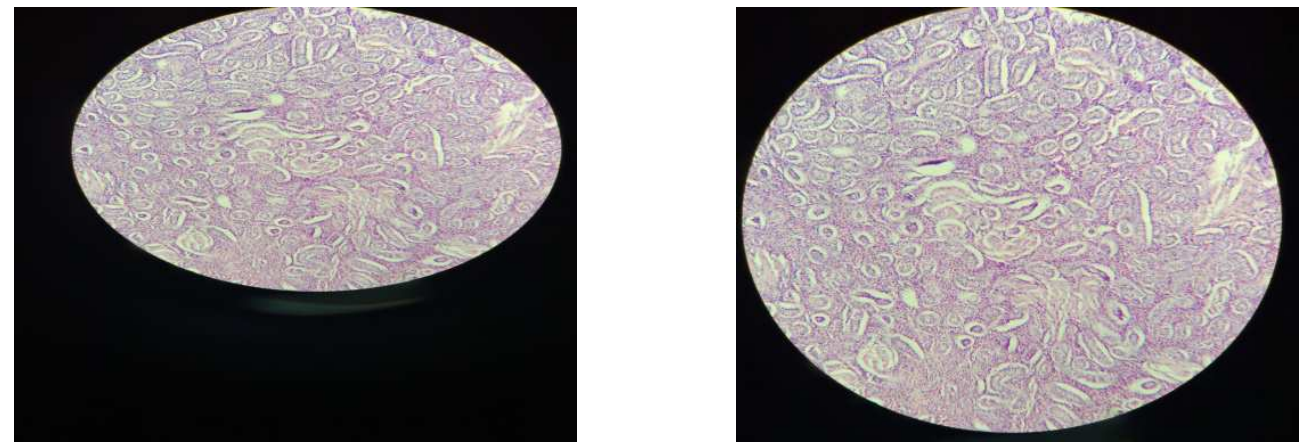

SertoliLeydig Cell Tumor Left Ovary (Left image-10x; H\&E) (Right image- 40x; H\&E)
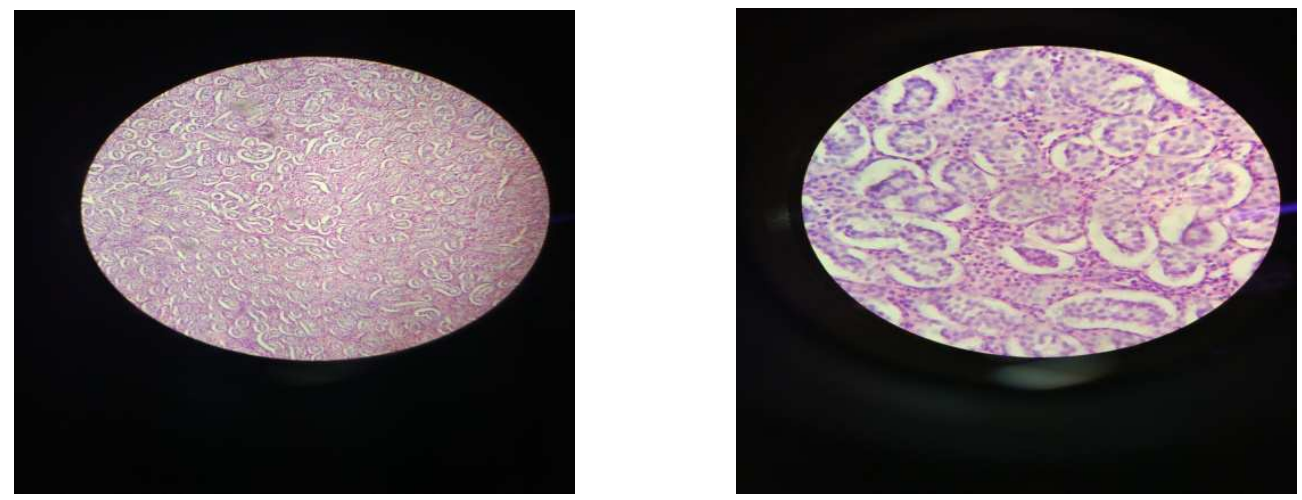

SertoliLeydig Cell Tumor Right Ovary (Left image- 10x; H\&E) (Right image- 40x; H\&E)
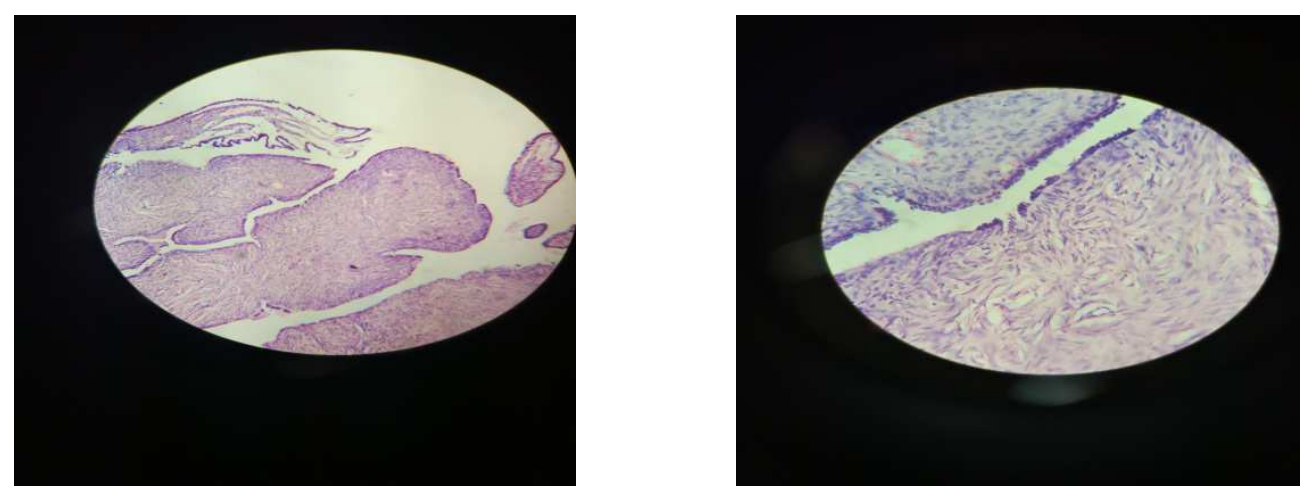

Serous Surface Papilloma Left Ovary (Left image- 10x; H\&E) (Right image- 40x; H\&E

\section{Discussion}

Sertoli-Leydig Cell Tumor (SLCT) is a rare ovarian tumor belonging to the group of sex-cord stromal tumors. These constitute less than $0.5 \%$ of ovarian tumors and are usually unilateral[1]. Our case is thus rare in having a bilateral presentation of the same. According to WHO classification, there are five subtypesof Sertoli-Leydig Cell Tumors according to the neoplastic Sertoli and Leydig cells exhibiting varying degrees of differentiation, which include welldifferentiated, moderately differentiated, poorly differentiated, retiform and with heterologous elements. The stage and degree of differentiation are the most 
important prognostic factors in these tumors. In 1985, Young and Scully reviewed 207 cases; of which all well-differentiated tumors were benign, $11 \%$ of tumors with intermediate differentiation, 59\% of tumors with poor differentiation, and $19 \%$ of those with heterologous elements were malignant [1]. Clinicallythey present with signs related tomostly androgen production like hirsutismand rarely estrogen [3], or symptomsof mass-occupying lesion as pelviabdominal mass and/or pain $[1,4,5]$. Testosterone and androstenedione levels are elevated in approximately $80 \%$ of patients with ovarian Sertoli-Leydig Cell Tumors withvirilizing manifestations $[6,7]$.

Our case also has the unusual finding of a 46XY karyotype with the patient being phenotypically female, a finding consistent with Swyer syndrome. Swyer syndrome is a pure gonadal dysgenesis syndrome with 46 XY karyotype, primary amenorrhea, presence of female internal genital tract and bilateral streak gonads in a phenotypic female [8]. There is a testicular differentiation abnormality in Swyer syndrome [9]. They have also elevated gonadotropins and hypoplastic gonads without germ cells [10]. The diagnosis is usually made at adolescence when the primary amenorrhea is investigated [8]. Gonadoblastomais the most common tumor that develops in Swyer syndrome [6, 7]. We could not comment on the streak gonads in our case due to the presence of mass in both the gonads.

Sertoli-Leydig Cell Tumors are mostly unilateral and diagnosed in stage I, so young patientsare treated with conservative surgery [11]. For patients with poor prognostic factors, adjuvant chemotherapy is considered. The BEP regimen i.e., bleomycin, etoposide, and cisplatin regimen does not affect the fertility status of the patientand is thus considered safe. Sertoli-Leydig Cell Tumor should always be taken into consideration in a young female patient with symptoms of virilization and an ovarian mass. The histopathology of the tumor decides the line of management; poorly differentiated tumors require aggressive management because of the high chances of them being malignant and intermediately differentiated tumors need an individualized approach [12].

\section{Conclusion}

This is a rare case of bilateral Sertoli-Leydig Cell Tumor. Primary amenorrhea with pain abdomen led to further investigations, which revealed left ovarian cyst with mural nodules and rudimentary uterus on transvaginal ultrasound and 46XY karyotype on cytogenetic study. Microscopic examination of sections from the specimen obtained by bilateral gonadectomy with left sided cystectomy revealed well-differentiated Sertoli-Leydig Cell Tumor in bilateral gonads. Presence of 46XY karyotype, primary amenorrhea, normal stature and rudimentary uterus were consistent with Swyer syndrome but we could not comment on the presence of streak gonads due to the presence of mass in bilateral gonads.

\section{Funding: Nil, Conflict of interest: None Permission of IRB: Yes}

\section{Reference}

1. Young RH, Scully RE. Ovarian Sertoli-Leydig cell tumors.A clinicopathological analysis of 207 cases. Am J Surg Pathol.1985Aug;9(8):543-69.

2. Dietrich JE, Kaplan A, Lopez H, Jaffee I. A case of poorly differentiated Sertoli-Leydigtumour of the ovary. J PediatrAdolesc Gynecol. 2004 Feb; 17(1):4952. DOI: 10.1016/j.jpag.2003.11.006

3. K. M. Zanotti, "The clinical manifestations and diagnosis of Sertoli-Leydig cell tumors of the ovary," CME Journal of Gynecologic Oncology 2002; 7: 129-133.

4. Zaloudek C, Norris HJ. Sertoli-Leydigtumors of the ovary. A clinicopathologicstudy of 64 intermediate and poorlydifferentiatedneoplasms.Am J SurgPathol. 1984 Jun; 8 (6):405-18.

5. Roth, L.M., Anderson, M.C., Govan, A.D.T., Langley, F.A., Gowing, N.F.C., and Woodcock, A.S. Sertoli-Leydig cell tumors. A clinicopathologic study of 34 cases. Cancer. 1981 Jul 1; 48(1):187-97 [PubMed] DOI: 10.1002/1097-0142 (19810701) 48:1 $<187::$ AID-CNCR2820480130>3.0.CO;2-1

6. Weng C.S., Chen M.Y., Wang T.Y., Tsai H.W., Hung Y.C., Yu K.J., Chiang Y.C., Lin H., Lu C.H., Chou H.H. Sertoli-Leydig cell tumors of the ovary: a Taiwanese gynecologic oncology group study. Taiwan. J. Obstet. Gynecol. 2013 Mar;52(1):66-70.[PubMed] doi: $10.1016 /$ j.tjog.2012.03.001.

7. V. W. Chen, B. Ruiz, J. L. Killeen, T. R. Coté, X. C. $\mathrm{Wu}$, and C. N. Correa, "Pathology and classification of 
ovarian tumors," Cancer, vol. 97, supplement 10, pp. 2631-2642, 2003.

8. Nisolle M, Kridelka F, Fridman V, Claudot A, Lorquet S, Foidart JM. [A bilateral dysgerminoma: a rare presentation of the Swyer syndrome]. Rev Med Liege. 2005 Sep;60(9):703-6.

9. Marrakchi A, Belhaj L, Boussouf H, Chraibi A, Kadiri A. [Pure gonadal dysgenesis $\mathrm{XX}$ and $\mathrm{XY}$ : observations in fifteen patients]. Ann Endocrinol (Paris). 2005 Dec; 66(6):553-6.

10. Ben Romdhane K, Bessrour A, Ben Amor MS, Ben Ayed M. [Puregonadal dysgenesis with 46 XY karyotyping (Swyer'ssyndrome) with gonadoblastoma, dysgerminoma and embryonal carcinoma]. Bull Cancer. 1988;75(3):263-9.

11. Kriplani A, Agarwal N, Roy KK, Manchanda R, Singh MK. Laparoscopic management of SertoliLeydig cell tumors of the ovary. A report of two cases. J Reprod Med. 2001 May;46(5):493-6.

12. RimpyTandon, M, PoonamGoel, Pradip Kumar Saha, NavneetTakkar, RPS Punia A Rare Ovarian Tumor - Sertoli-Leydig Cell Tumor With Heterologous Element. MedGenMed. 2007; 9(4): 44

\section{How to cite this article?}

Dutta A, Borah S.R, Saikia P, Taye M. Case report of sertoli-leydig cell tumor of bilateral ovaries in a woman with 46XYkaryotype. Int J Med Res Rev 2017;5(05):495-498. doi:10.17511/ijmrr. 2017.i05.10. 